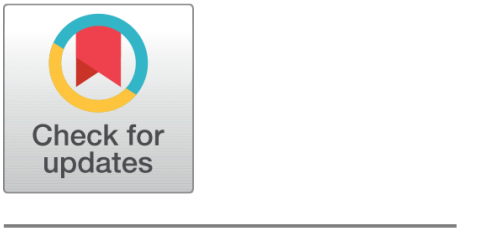

OPEN ACCESS

Received: 16-07-2020

Accepted: 25-07-2020

Published: 07-08-2020

Editor: Dr. Natarajan Gajendran

Citation: Lalitha RVS, Srinivas R, Kumar PSVVSR, Kavitha K, Sameera PVSNS (2020) Intelligent signalling system to control traffic in vehicular ad hoc networks. Indian Journal of Science and Technology 13(28): 2876-2882. https://doi.org/ 10.17485/IJST/V13i28.1043

*Corresponding author.

rvslalitha@gmail.com

Funding: None

Competing Interests: None

Copyright: @ 2020 Lalitha et al.. This is an open access article distributed under the terms of the Creative Commons Attribution License, which permits unrestricted use, distribution, and reproduction in any medium, provided the original author and source are credited.

Published By Indian Society for Education and Environment (iSee)

ISSN

Print: 0974-6846

Electronic: 0974-5645

\section{Intelligent signalling system to control traffic in vehicular ad hoc networks}

\author{
R V S Lalitha1* ${ }^{*}$, R Srinivas $^{2}$, Pullela SVVSR Kumar ${ }^{3}$, K Kavitha $^{4}$, \\ P V S N S Sameera 5
}

1 Professor, Department of C.S.E, Aditya College of Engineering \& Technology, Surampalem, 533 437, India

2 Professor, Department of C.S.E, Aditya Engineering College, Surampalem, 533 437, India

3 Professor, Department of C.S.E, Aditya College of Engineering, Surampalem, 533 437, India

4 Associate Professor, Department of C.S.E, Gokaraju Rangaraju Institute of Engineering \&

Technology, Hyderabad, 500 090, India

5 Software Engineer, TCS, Bangalore, India

\section{Abstract}

Traffic congestion problem persists more at junctions and causes inconvenience to public. Owing to this, people may not reach their destinations in time. Although there are alerts in mobile phones regarding arrival times of flight services and other journey related information due to sudden traffic jams at junctions these advanced technology innovations are being becoming fragile. Since long, many researchers have been putting their efforts to find remedies for reducing traffic congestion. Objectives: The key focus is on balancing forwarding time and waiting time at junctions based on the number of vehicles arrived at that junction. Methods: The proposed system uses Internet of Things (IOT) based monitoring to control signaling system. IR sensors are used to count number of vehicles passing over the lane by triggering clock for object detection. The signaling time can be changed dynamically based on the vehicle count, so that more time is allocated to the lanes which have more traffic and the remaining time is adjusted among other lanes. This reduces congestion at dense traffic lanes. Findings: There will be time variant setting of signal lights based on the density of the traffic. The dense traffic lanes will be allotted more time and will be cleared first. Expanding on this point, the time adjustment is done based on the vehicle count not on periodical fixation of intervals. Novelty: The ecosystem developed provides an ultimate solution to vehicle users for comfortable movement on the roads without being delayed.

Keywords: Traffic density; IR Sensor; VANET; ITS; IoT; clock

\section{Introduction}

The exponential increase in the number of vehicles leads to transportation issues. Due to flooding of vehicles and signaling intervals vehicles are forced to wait at junctions. The performance of the road clearing mechanisms is to be improved to avoid roundabout travels. Research was being worked on finding optimal path. The optimal 
path calculations assist drivers in reducing trip time of travel ${ }^{(1)}$. The popularly used congestion control mechanisms are proactive and reactive. Proactive mechanisms 
estimate traffic density in advance whereas in reactive mechanism, the actions will be performed after arrival of congestion ${ }^{(2)}$. The key issue focused in this paper is waiting time at road junctions by dense lanes. Current day signaling system allots fixed timing for all four lanes. Though there is no traffic at sparse lanes, busy lanes need to wait for their turn to come. This exaggerates the congestion issues. The present traffic signaling systems have some draw backs as they operate at fixed time intervals. In this paper an eco-system is developed that calculates dynamically the interval time based on the vehicle count detected by IR sensors. The span of the interval is divided in such a way that more time to busy lane and the remaining to be adjusted for the other three lanes. In Section 2, the relative carried out by the researchers is explored. Section 3 describes about implementation mechanism, architecture and its working principle. In Section 4 the screen shots of typical scenarios are explained and finally concluded with the significance of our research and its benefits.

\section{Related work}

Badreddine Cherkaoui elaborated congestion problems in VANETs using Big data tools. The dynamic state of the traffic is circulated across the network through V2V communication. He explored the problem of congested roads and set of all roads using the equation $\mathrm{Q}=\mathrm{K}^{\star} \mathrm{U}$ where $\mathrm{Q}$ is route, $\mathrm{K}$ is capacity of route and $\mathrm{U}$ is the speed of flow. The situation was analyzed using NS2 simulator ${ }^{(3)}$. Rayman Preet Singh evaluated traffic congestion problem using Beacon relevance. In his paper he discussed about two types of congestions. The current state of the traffic can be evaluated using instantaneous congestion and the state of neighboring vehicle was used for stabilized local congestion ${ }^{(4)}$. M.Monica Bhavani presented a solution using GIS for detecting heavy traffic dense areas like shopping malls. Alternate routes can be tracked and displayed using VANET communication methodologies ${ }^{(5)}$. Pampa Sadhukhan addressed the problem traffic congestion using IoT. The signaling system set is based on the measured traffic density based on time based intervals ${ }^{(6)}$. Ayesha Ata analyzed the traffic congestion problem using IoT and Machine Learning. Also SVM is applied to analyzed traffic congestion analysis. Traffic congestion at particular point was also notified ${ }^{(7)}$. Duc-Binh Nguyen proposed fuzzy based traffic congestion algorithm based on velocity of the vehicle and congestion coefficient. Traffic flow using MQTT broker architecture was also discussed and studied. He developed two interfaces one for client side and the other for monitoring unit ${ }^{(8)}$. Yucheng Huang proposed novel approach for analyzing traffic congestion using IoT based wireless sensor system. The system used wireless accelerometers for determining traffic volume and categorization of vehicles. Axle spacing and estimated speed were calculated numerically. The innovative solution of classification of vehicle monitoring system using wireless sensor networks and IoT were well illustrated ${ }^{(9)}$. IoT based traffic signaling system using Arudino, Raspberry Pi and ultrasonic sensors helps in formation of VANETs. The traffic information can be viewed by the web page by the police for necessary action. The controlling of signals will be based on the density of the traffic ${ }^{(10)}$. The significance and use of Raspberry $\mathrm{Pi}$ and sensors plays vital role for calculating traffic density ${ }^{(11)}$. IoT based Traffic signaling system uses traffic data for forwarding to next junction ${ }^{(12)}$. The congestion detection using inductive loops is not effective due to its error in its functionality. Another mechanism is by using magneto meter. Due to change in earth's magnetic field also, it is susceptible to error rate. Real time traffic detection using camera is preferable and can be analyzed. The cameras may not detect object in times of bad weather. The congestion detection had been proposed using inductive loops, magnetometers, video streaming and radar. The challenge is to minimize congestion at road junctions. This paper presents a novel solution, wherein the timing of traffic signals is set based on sensing of real time traffic. This paper has been extension to micro controller based traffic signals. In this mechanism, signal time is fixed. In our proposed methodology, the time variant mechanism of traffic signaling is implemented and is tested in the institution itself.

The system allows dense traffic to be cleared first and is allotted more time. The remaining amount of interval time is distributed for the other three lanes dynamically. The object count determines the traffic density and based on that signaling time will get changed.

\section{Methodology}

The ecosystem is developed using Raspberry Pi, IR Sensors, 40 pin PIC16F877A Microcontroller, 16 pin MCP3008 IC and LED Lights. The circuit diagram is shown in Figures 1, 2 and 3 and architectural view is shown in Figure 4 . The common drawback of IoT based systems is that there may be chance of failure of IR sensors. That is when sensor fails there will be chances of improper timing of signaling. This has been taken care in this paper by verifying sensor detection with manual detection once in a fortnight. Also the functioning of sensors is cross verified by erecting more number of IR sensors, and comparing the sensing information of each.

The pin connections of sensors and power supply are as given below: 


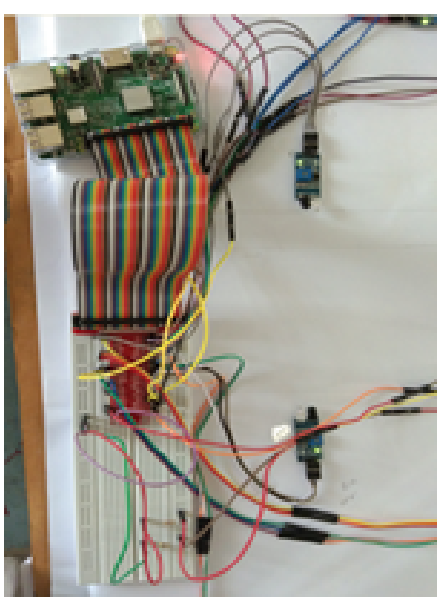

Fig 1. Circuit diagram.

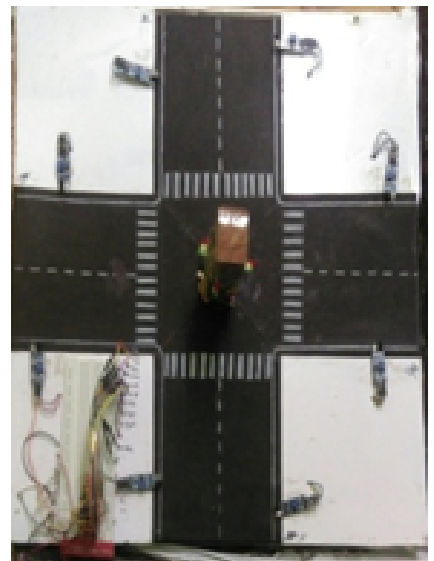

Fig 2. Eco system for controlling traffic lights

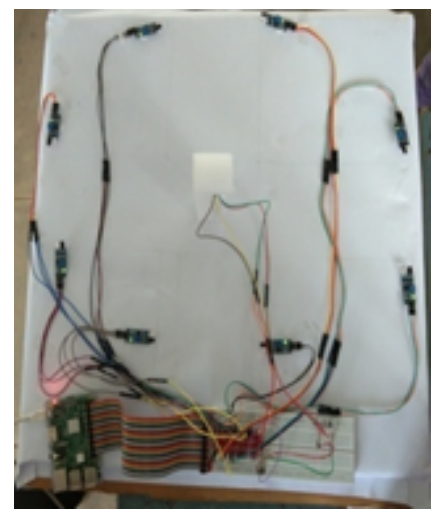

Fig 3. Erection of IR Sensors on road side. 


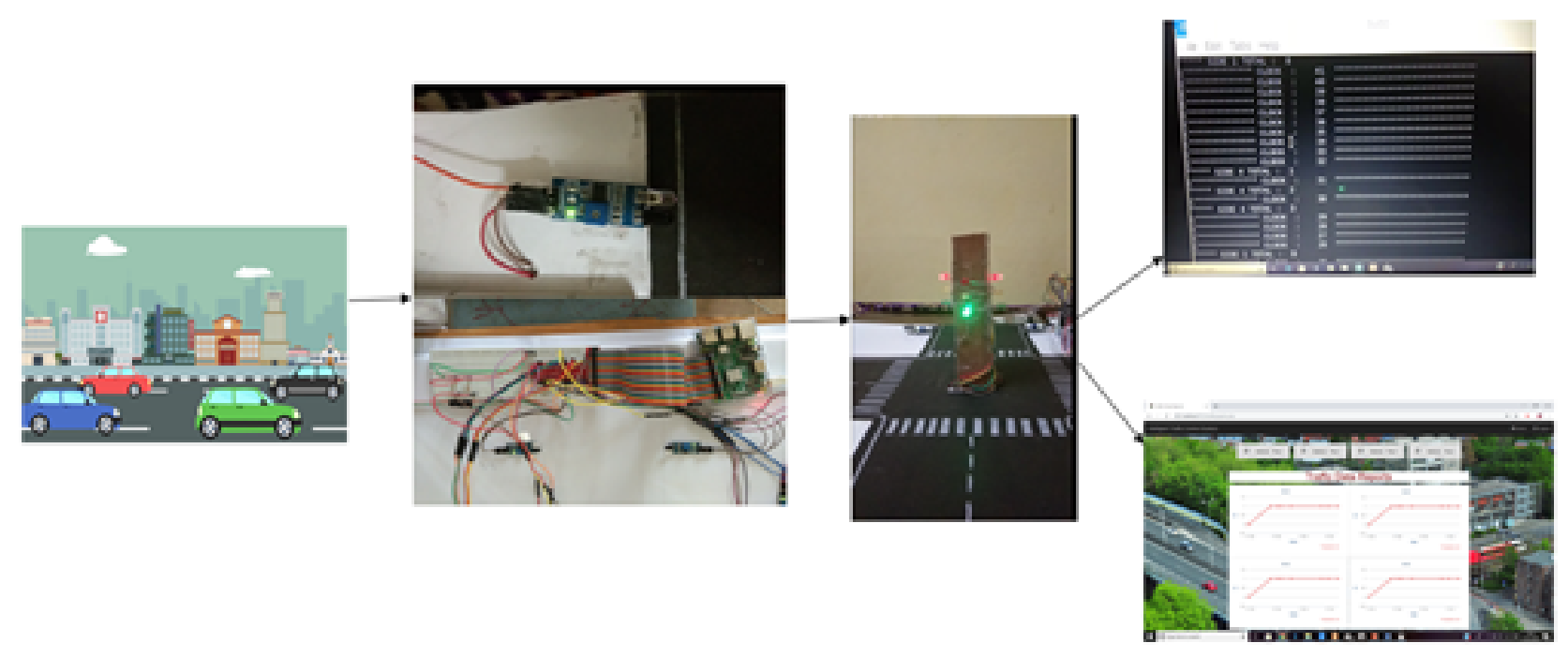

Fig 4. Intelligent Traffic Control System

\subsection{Pin connections for sensors :}

- Side 1 first IR sensor output pin - GPIO pin 21 of Raspberry Pi

- Side 1 second IR sensor output pin - GPIO pin 22 of Raspberry Pi

- Side 2 first IR sensor output pin - GPIO pin 23 of Raspberry Pi

- Side 2 second IR sensor output pin - GPIO pin 24 of Raspberry Pi

- Side 3 first IR sensor output pin - GPIO pin 25 of Raspberry Pi

- Side 3 second IR sensor output pin - GPIO pin 27 of Raspberry Pi

- Side 4 first IR sensor output pin - GPIO pin 28 of Raspberry Pi

- Side 4 second IR sensor output pin - GPIO pin 29 of Raspberry Pi

- For all sensors and LEDs connect GND pin - pin number 40 of Raspberry Pi

- For all sensors and LEDs connect VCC pin - pin number 17 of Raspberry Pi

- Give power supply to all the LED's with $100 \mathrm{~K}$ ohm resistor to the LED's Anode.

\subsection{Pin connections for Power supply}

- Side 1 LED's anode i.e., Red - pin number 40 of Raspberry Pi

- Side 1 LED's anode i.e., Yellow - pin number 1 of Raspberry Pi

- Side 1 LED's anode i.e., Green - pin number 2 of Raspberry Pi

- Side 2 LED's anode i.e., Red - pin number 3 of Raspberry Pi

- Side 2 LED's anode i.e., Yellow - pin number 4 of Raspberry Pi

- Side 2 LED's anode i.e., Green - pin number 5 of Raspberry Pi

- Side 3 LED's anode i.e., Red - pin number 12 of Raspberry Pi

- Side 3 LED's anode i.e., Yellow - pin number 13 of Raspberry Pi

- Side 3 LED's anode i.e., Green - pin number 14 of Raspberry Pi

- Side 4 LED's anode i.e., Red - pin number 6 of Raspberry Pi

- Side 4 LED's anode i.e., Yellow - pin number 10 of Raspberry Pi

- Side 4 LED's anode i.e., Green - pin number 11 of Raspberry Pi

- Short end of all LED's i.e., cathode - the GND pin 40 of Raspberry Pi 
Initially, signal time is set to $15 \mathrm{Sec}$. If the vehicle passes over the junction, IR Sensor senses the object and sends information to LED circuitry. If the signal time is fixed, the vehicles in the busy lane need to wait, even though there is no traffic in those lanes. As a refinement, the signal time is set based on the vehicle count on four lanes. A green signal of $25 \mathrm{sec}$ for the busy lane is set and making other lanes wait for the rest of the time. The timing of signals is calculated using the following rules:

Rule 1: If the number of vehicles in the lane1>lane2, lane3 and lane4, then more time will be allocated for lane1

digitalWrite(s1red,1); digitalWrite(s1yellow,0); digitalWrite(s1green,0);

Rule 2: If the number of vehicles in the lane2>lane1, lane3 and lane4, then more time will be allocated for lane 2 then set LED indication as: digitalWrite(s2red,1); digitalWrite(s2yellow,0); digitalWrite(s2green,0);

Rule 3: If the number of vehicles in the lane $3>$ lane1, lane 2 and lane4, then more time will be allocated for lane 3 then set LED indication as:

digitalWrite(s3red,1); digitalWrite(s3yellow,0); digitalWrite(s3green,0);

Rule 4: If the number of vehicles in the lane4>lane1, lane 2 and lane3, then more time will be allocated for lane 4 then set LED indication as: digitalWrite(s4red,1); digitalWrite(s4yellow,0); digitalWrite(s4green,0);

\section{Results}

The vehicle count using IR sensors is depicted in Figure 5 shows vehicle detection and Figure 6 shows traffic count in each lane. shows the sorts the densities of traffic in each lane. The design of eco system is best suited for allocating highest time to the road which is having high traffic. The priorities are chosen based on the traffic density sensed by IR sensors. The benefit of this eco system is reduction of waiting time at junctions. More time is to be assigned for dense traffic lanes whereas less traffic for other lanes.

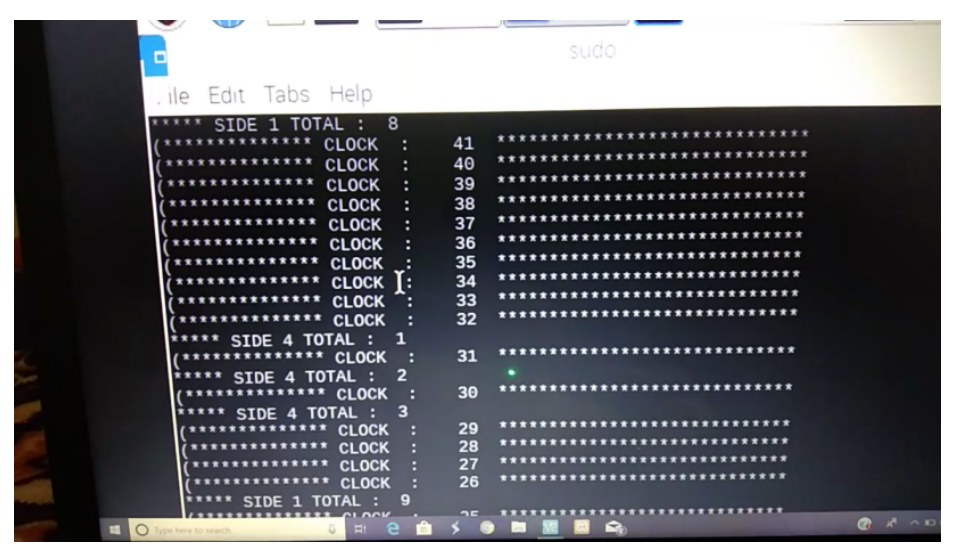

Fig 5. Detection of vehicles on each lane using IR sensors

\section{Conclusion}

The ecosystem developed is a solution to the traffic congestion problem using the principles of Intelligent Traffic Control System using IOT. This ecosystem results in controlling the traffic in an effective and smarter way and is beneficial to the society and government.

\section{References}

1) Toulni H, Nsiri B, Boulmalf M, Bakhouya M, Sadiki T. An approach to avoid traffic congestion using VANET. In: and others, editor. International Conference on Next Generation Networks and Services (NGNS), 28-30 May 2014. IEEE. 2014. Available from: https://doi.org/10.1109/NGNS.2014. 6990245.

2) Liu W, Chen Y, Wu X, Tan Z. Average Real Variability of Diastolic Blood Pressure During Acute Phase Could Independently Predict 3-month Functional Outcome for Ischemic Stroke. American Journal of Internal Medicine. 2020;8:107-107. Available from: https://dx.doi.org/10.11648/j.ajim.20200803.13.

3) Cherkaoui B, Beni-Hssane A, Fissaoui ME, Erritali M. Road traffic congestion detection in VANET networks. Procedia Computer Science. 2019;151:11581163. Available from: https://dx.doi.org/10.1016/j.procs.2019.04.165.

4) Singh RP, Gupta A. Traffic Congestion Estimation in VANETs and Its Application to Information Dissemination. In: and others, editor. International Conference on Distributed Computing and Networking, ICDCN 2011: Distributed Computing and Networking. ;p. 376-381. Available from: https: //doi.org/10.1007/978-3-642-17679-1_33. 


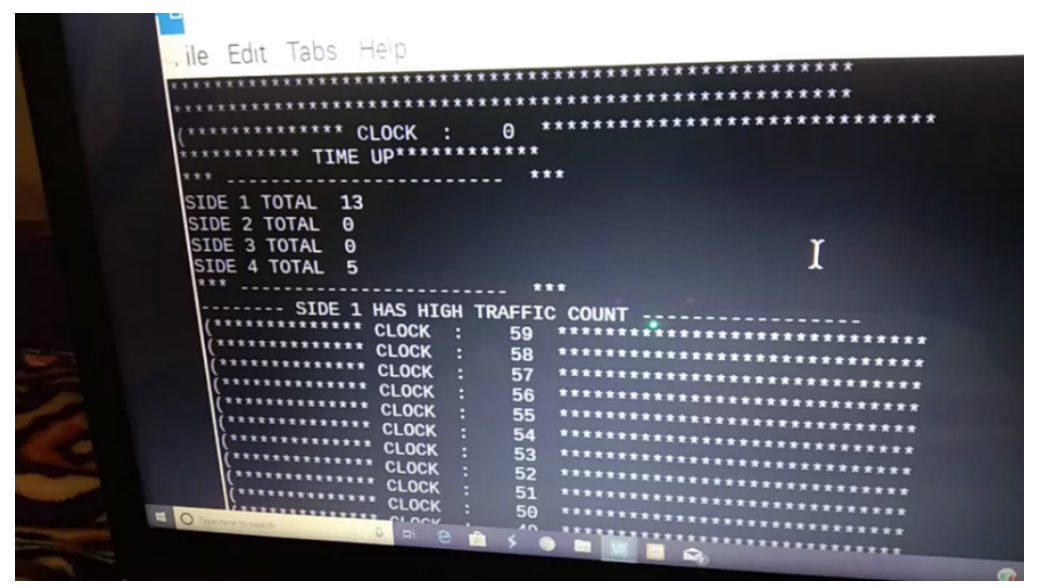

Fig 6. Analyzing dense traffic lanes for changing timing intervals.

5) Bhavani MM, Valarmathi A. Smart city routing using GIS \& VANET system. Journal of Ambient Intelligence and Humanized Computing. 2020. Available from: https://dx.doi.org/10.1007/s12652-020-02148-y.

6) Sadhukhan P, Gazi F. An IoT based Intelligent Traffic Congestion Control System for Road Crossings. In: and others, editor. 2018 International Conference on Communication, Computing and Internet of Things (IC3IoT), 15-17 February. 2018;p. 15-17. Available from: https://doi.org/10.1109/IC3IoT.2018. 8668131

7) Ata A, Khan MA, Abbas S, Khan MS, Ahmad G. Adaptive IoT Empowered Smart Road Traffic Congestion Control System Using Supervised Machine Learning Algorithm. The Computer Journal. 2020. Available from: https://dx.doi.org/10.1093/comjnl/bxz129.

8) Nguyen DB, Dow CR, Hwang SF. An Efficient Traffic Congestion Monitoring System on Internet of Vehicles. Wireless Communications and Mobile Computing. 2018;2018:1-17. Available from: https://dx.doi.org/10.1155/2018/9136813.

9) Huang Y, Wang L, Hou Y, Zhang W, Zhang Y. A prototype IOT based wireless sensor network for traffic information monitoring. International Journal of Pavement Research and Technology. 2018;11(2):146-152. Available from: https://dx.doi.org/10.1016/j.ijprt.2017.07.005.

10) Ashok S, Sankari VS, Mani S, Sankaranarayanan. IoT Based Traffic Signalling System. International Journal of Applied Engineering Research. 2017;12:82648269.

11) Talukder MZ, Towqir ASS, Remon R, Hasan U, Zaman. An IoT based automated traffic control system with real-time update capability. In: IEEE Conference. 2017;p. 3-5. Available from: https://doi.org/10.1109/ICCCNT.2017.8204095.

12) Basil E, Sawant SD. IoT based traffic light control system using Raspberry Pi. In: 2017 International Conference on Energy, Communication, Data Analytics and Soft Computing (ICECDS), IEEE Conference. 2017;p. 1-2. Available from: https://doi.org/10.1109/ICECDS.2017.8389604. 